\title{
ASPECTOS DA AVALIACÃO INSTITUCIONAL DOS PROGRAMAS DE PÓS-GRADUAÇÃO EM DIREITO: INSTRUMENTOS E CONCEPÇÓES
}

Luiz Edson Fachin e

Maria Francisca Cameirol

SUMARIO: 1. Introduço - 2. Consideraçoes acerca da avaliaça dos programas de pósgraduaço no Brasil2. 1 Aspectos recentes da avaliaca institucional no Brasil e no mundo 2.2 Observaços sobre o caso brasileiro - 23 Reflexoes sobre a avaliaça dos cursos de posgraduaça cm Direito - 3. Avaliaça como procedmento em educacão : 3.1 o binomio quantidadqualdade no processo de avahaca -3.20 dfol (mas possivel) dialogo micro-macro - 3.3 Taxonomids, objetivos e hierarquizaco - 4. Breve nota à gitsa de conclusăo - 5 . Referencias Bibliograficas

RESUMO: Este trabaho trata de elementos que contribuem para discutir aspectos do conceito de avaliaço educacional, em seus fundamentos historicos e sociologicos, verificando-se quais as razöes do privilégio de alguns métodos em detrimento de outros. Aborda-se as principais tendencias de avaliaça institucional no panorama mundial, relacionando-as con as caracteristicas apresentadas pelo intrumento nacional DATACAPES. Apresenta-se uma preliminar sugestão de alguns elementos que podem ser eventualmente considerados, para o prosseguimento da pesquisa em avaliação nos cursos de pósgraduaço em Direito. Analisa-se os criterios quantitativos $e$ qualitativos de avaliaço, en suas virtudes, problemas e questoes. Considera-se as dificuldade insitucionais nas telaçoes entre o micro e o macro sistema social, no contexto da avaliaça, ben como a inevitabilidade das taxonomias, do estabelecimento e heraratizacao de objetivos em avaliacäo educacional.

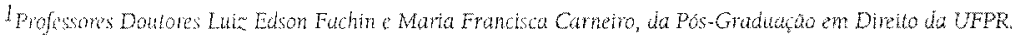


PALAVRAS-CHAVE: Avaliaço Institucional, Instrumentos, Concepços.

ABSTRACT: This essay deals with the elements that contribute to the discussion of the aspects of the educational evaluation concept in its historical and sociological fundaments, verifying what are the reasons for the privilege of some methods in despite of others. It also works with the most important culencies of the institutional evaluation in the world, relating them to the characteristics presented by the national instrument DATACAPES.

Besides, it presents a preliminary suggestion of some elements the may be cventually considered, for the progressing of the research in evaluation in the post graduation law courses.

It andyses the quantitative and qualitative criteria of evaluation in its virtues, problems and questions.

Finally, it considets the institutional diffoulties in the relations between the micro and macro social system, in the context of the evaluation, as well as the inevitability of the taxonomy, the establishment and herarchy of the goals in educational evaluation.

\section{CONSIDERAÇÕES ACERCA DA AVALIAÇÃO DOS PROGRAMAS DE PÓS-GRADUAÇÃO NO BRASIL}

F alar sobre a avaliaça do ensino de terceiro grau, no Brasil, incluidas as pós-graduaçoes, implica também em pensar a funcão social da universidade em nosso Pais.

O debate, do qual a universidade é o centro e que engloba as questoes da autonomia, legitimidade, politica financeira, problematica social, etc., so laz por ressaltar a importancia e o papel que exerce a universidade. Diz AMORIN2:

A Sociologia da Educacão sempre reconheceu duas dimensöes importantes na relaço sistema de ensino-sociedude: que o sistema de ensino, em aualquer nivel

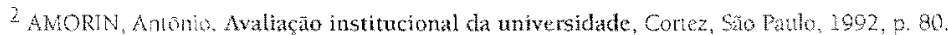


"serv" a sociedade ha qual esta inserido, que este sistema (espectalmente em seu nuel superior) goza de razoável autonomia, mantendo uma relaça "criativa" com a sociedade.

\subsection{Aspectos recentes da avaliaçāo institucional no Brasil e no mundo}

A avaliacajo institucional nas universidades brasileinas e latinomericanas, em geral, é uma realidade relativamente recente, se comparada ao cue ocorre nos paises europeus.

Em válios países do mundo, pode-se dizer que, em nossos dias, essa ativiclade transita em torno de dois grandes subsunçores: autonomia e oualidade.

A Franca, na tentativa de solucionar o problema da ingerencia estatal na avalacăo das universidades - porque esta tarela era realizada por órgão do govemo lederal - criou a figura dos "pares", avaliadores que intermediam as instituicoes e o governo. No Brasl, com algumas adaptaçes, essa modalidade inspirou a criaça dos professores avaliadores da CAPES e os consultores do CVPq, por exemplo.

A Inglaterra, com uma tradição secular de autonomia, considerava como desastrosa qualquer intervençăo do Estado nas universidades. O interméclio era leito por "acordos de cavalheiros" celebrados entre as partes, atraves do ógà U.G.C. (University Grantes Comunitee), hoje menos lontalecido e talvez atropelado pelos intensos ritmos da globalizacăo e suas relaçóes de produçäo, sociedade e mercado. Uma recente tendéncia, no panorama europeu ${ }^{3}$ é o surgimento de um evaluative state, como interessante alternativa para os países com forte tradicäo de um Estado avaliador (como, por exemplo, a França). Para essa modalidade, a avaliação institucional, realizada pelo governo, náo é desenvolvida com base em um planejamento a mion c burochitico, estabelecido pelo governo; mas sim a posteriori, em que se busca atingir padroes de desempenho indicados pela sociedade como um

\footnotetext{
3 NEAV Gin: On the cultivation of quality, efficiency and enterprise and overview of recent trends in higher education in Lurope, 1986-1988, Luropean Journal of educations, 23, 1ane 2, 1988, pp. 7-24, aptad SCOHWATZMAN, Simon. O contexto institucional e político da avaliação, in DURHAM, Eunce Re SCHWhETZMAN, Simon, (orgs). Avaliacão do ensino superior, Ed. USP, São Paulo, 1992 , p. 14.
} 
todo. Esses mecanismos, quanto ao "estado de arte", ensejam estudo e desenvolvimento, principalmente porque implicam em uma grande discussão na inversão funcional do conhecido binômio planejamento/avaliação.

Ainda sobre a tendência atual dos movimentos de avaliação no ensino superior, ouçamos PEUKERT4:

Hoy se tiene cada vez más la impresión de que nos hallamos ante el umbral de una época histórica en la que todas las anteriores interpretaciones y orientaciones se cuestionan. Para la visión histórica se dibujam los contornos de un espacio histórico, y cada vez son más claras las tendencias fundamentales que lo determinan. Lo que en el fondo nos permite hablar de una especie de iumbral epocali caracterizado por la crisis, es la impresión de que son precisamente las repercusiones de la modernidad, en cuanto desarrollo social que en su dinámica se supera continuamente a si mismo, las que vuelven sobre ella poniéndola en peligro. Al amenazarse a si misma, la modernización, en cuanto movimiento histórico, se hace asi objetivamente reflexiva.

O que se observa, nitidamente, é que a pesquisa educacional em avaliação não cessa; ao contrário, é cada vez mais intensa, especialmente em se tratando de universidades e pós-graduações, por causa da maior estreiteza com o mercado de trabalho e as suas relações com a produção de ciência.

\subsection{Observações sobre o caso brasileiro}

A avaliação dos cursos de pós-graduação, no Brasil., foi recentemente atualizada através da edição do formulário DATACAPES que, em substituição ao EXECAPES, mostra-se mais fluído e dinâmico, permitindo leituras diversificadas da realidade institucional avaliada e possibilitado o cruzamento de múltiplos códigos como tópicos de conteúdo.

Nesse sentido, pode-se dizer que o instrumento DATACAPES, em sua descriçăo, pode ser comparado aos contemporâneos modelos norteamericanos e europeus, que procedem às mensurações quantitativas

\footnotetext{
4 PEUKERT, Helmui. Las ciencias de la educación de la modernidad y los desafíos del presente (in Educación, vol. 49-50), Intituto de Colabonción Científica, Tübinger, 1994.
} 
complexas através de "rotas" ou fluxos de informaçoes, permitindo conjugaçoes, disjunçōes ou injunçōes das" performances entre $\mathrm{si}^{5}$.

Observa-se também que o aparato brasileiro de avaliaçăo de pósgraduação, no fito de atender à demanda pela qualidade e produção (no caso, do saber), não descura da influência das pesquisas em organizaçöes ${ }^{\circ}$.

Se analisado sob o prisma dos modelos atuais de avaliação de currículo, O DATACAPES aproxima-se das características da chamada "avaliação responsiva", de $\mathrm{STAKE}^{7}$, em virtude das respostas que busca às questões previamente formuladas.

No entanto, ainda que avançadissimo em seus pressupostos, tanto quanto em suas metodologias, O DATACAPES continua privilegiando as observaçoes quantitativas quanto à aferição, tabulação e padronização dos dados levantados.

Aponta-se também que a pesquisa em avaliação educacional näo cessa. Ao contrário, intensifica-se e avança cada vez mais, especialmente em se tratando de pós-graduação, em virtude da estreita relação com as formas de produçào e transformaçăo social?.

Por essa razão, indaga-se sobre a possibilidade da inclusäo de elementos qualitativos em formulários de cunho quantitativo. Para DAVIESO essa hipotese não é teoricamente recomendavel porque acarreta soluçóes de continuidade, na maioria das vezes insoluveis, no processo final de tabulacăo de dados. Alem disso, descanacteriza a natureza tanto de uma como da outra forma avaliativa.

A solução estaria, então, para esse autor ${ }^{11}$, na chamada avaliação progressiva, que consiste em uma transição entre as quantidades e as qualidades.

\footnotetext{
Infu, tem 3.3, Taxonomias, objetivos a hierarquização, p. 18

6. Infru, item 3., Avaliaçấo como procedimento em educação, p. 11.

${ }^{7}$ Infra, item 3. Avaliacăo como procedimento em educaça, p. 20 e segs

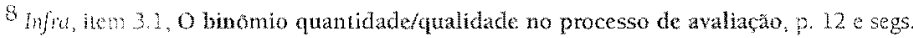

9 5trm, item 2., Aspectos recentes da avaliação institucional no Brasil e no mundo, p. 2 e segs.

10 DAviES, lwor Kevin. O planclanento de curriculo e seus objetivos (1rad. Matlia Lins e Nelio Parra), Sarava, Sto Patto, $1979,256$.

11. Idem, Ihidem.
} 
Além disso, a avaliação progressiva atende ao requisito fundamental qualitativo, que é a paulatinidade ${ }^{12}$.

\subsection{Reflexões sobre a avaliação dos cursos de pós-graduação em Direito}

Hipóteses experimentais de avaliação nos cursos de pós-graduação, podem adotar, por exemplo, padrões progressivos em direção à avaliação qualitativa, através de instrumentais compativeis com o DATACAPES ou outros modelos que emergirem como de interesse, das discussöes.

No caso especifico das pós-graduações em Dircito, os padrōes de avaliaçăo, em consonáncia com os pressupostos metodológicos da pesquisa, do ensino e da aplicação, näo poderiam descurar da especificidade do conhecimento jurídico, o que, por si só, ensejaria um estudo à parte.

Assim, poderiam as pós-graduaçoes em Direito criar seus "constructos" internos de avaliação, experimentá-los, discutílos, apreciar seus resulados e, desse modo, contribuir para o incremento do avanço da pesquisa nesse campo do saber, junto aos órgãos oficiais e em face das exigências micro e macro-sociais ${ }^{3}$.

Porcue, se para a metodologia contemporânea, o sentido está em percorrer caminhos plurais ${ }^{14}$, e na llexibilizaçäo ${ }^{15}$ que a cultura encontra, em nossos dias, um de seus principais aportes.

A seguir examinaremos alguns dos pressupostos teóricos que subsidiam o tema em estudo.

\section{AVALIACÃO COMO PROCEDIMENTO EM EDUCACÃO}

A avaliaça pode ser considerada uma atividade indissociável da educaçà en qualquer filosofia ou concepçào metódica. Portanto, não se faz

\footnotetext{
12 Infu, $11 \mathrm{~m}$ 3.1, O binomio quantidade/qualidade no processo de avaliaçăo, p. 12 e segs.

13 Infr. nem 3.2.0 diffil (mas possivel) dirlogo micro-macro, p. 16

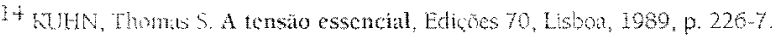

15 ESCOTEl, Migue Ange! Universidad y devenir - entre la certeza y lancertudmbre, Lugar Editorial, Buenos Airs, 1000, P. 100
} 
educação sem algum lipo de avaliação ${ }^{16}$.

Havemos de considerar, também, que a avaliação, em sentido amplo, encontra-se associada à experiencia cotidiana do ser humano. $\dot{E}$ frequente que nos deparemos avaliando circunstâncias, ambientes e comportamentos. Para SAUL17, "esta avaliação, que fazemos de forma assistemática, por vezes inclui uma apreciação sobre adequação, eficácia e eficiência de ações e experiências, envolvendo sentimentos e podendo ser verbalizada ou näo".

Na transposiçăo do "grau dóxico" da reatidade cotidiana para "grau epistêmico" da Educação, essa atividade, que é a avaliação, sofre sistematizaçóes que variam de acordo com os pressupostos teóricos sobre os quais se explicita, de acordo com os diferentes momentos da historia da educação. As variações ocorrem, ainda, conforme a complexidade teórica e prática que assumem algumas posturas e servem a múltiplos propósitos.

Observando-se o transcurso de parcela significativa da história da educaça, no Ocidente, verifica-se que até meados deste século, a avaliação estava centrada precipuamente sobre o rendimento da aprendizagem. Essa atitude é resultado do método escolástico, que, no acompanhamento do pensamento medieval, isolava aspectos e classificava-os em separado. Antes disso, na Antiga Grécia, a atividade de avaliação estava mais próxima da "totalidade", ja que a Paidéia pode ser entendida como o desenvolvimento integral da personalidade humana.

No início deste século, a literatura sobre avaliação como medida é predominante. Busca-se, nesse período, quantificar e mensurar a aprendizagem, tào-somente.

Na década de vinte, desenvolve-se, principalmente nos Estados Unidos da América, o movimento dos "testes educacionais". Essa vertente sustenta a avaliação de situaçóes comportamentais por medidas sempre quantitativas.

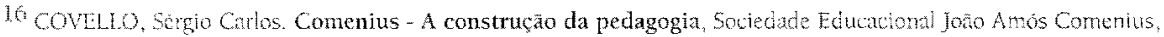

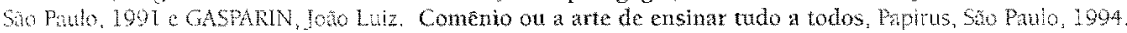

17 SAUL, An Matho Avaliacio emancipatoria - desafio à teoria e à pratica de avalacaco e reformulaça de wurriculo, 2 ch. Conez, 50 Paulo, 1991, p. 25.
} 
Na década de trinta, a idéia de mensuração por testes padronizados toma corpo e avança quanto à sistematização e complexidade. Os estudos avaliativos incluem uma série de procedimentos, tais como: escalas, testes, inventários, registros, técnicas estatísticas as mais diversas, questionários e outras listagens, para colher evidencias dos resultados do rendimento dos alunos em perspectivas longitudinais (porque quantitativas) e em relação a padróes previamente estabelecidos.

Como resultado da expansão industrial do pós-guerra, analogicamente ao que ocorre no processo de produção, a Educação passa a valonizar cada vez mais acentuadamente a atitude do aluno como fator de avaliação. Surge, assim, a diferença entre objetivos educacionais e instrucionais, como fatores de avaliação e com eles, a necessidade de outras formas dessa atividade.

A década de setenta, com a revolução dos costumes, a contracultura e todos os seus corolários, enseja o aparecimento da Escola Nova, em substituição à Escola Tradicional, como uma significativa inversão de valores pedagógicos. Surgem outras tentativas de avaliação que, por apregoarem a derrocada do sistema objetivo de medidas, podem tender para a relativização dos valores em detrimento da determinação dos objetivos, com o risco de culminarem na subjetividade. Talvez um possivel equivoco desse periodo tenha sido o de entender quantidades como sinonimo objetividade $e$ qualidades como tradução de subjetividade. Mais adiante, nesta comunicação, veremos como é essa confusăo

Fato é que a trajetória da avaliação educacional - agora mais complexa, com a inclusão de inúmeros aspectos como: produtividade, lideranças, atividades paralelas e integrativas do curriculo, além do rendimento específico näo só do ensino; mas da pesquisa e interesses afins, prossegue como sinonimo de medida e quantificação (não obstante as críticas que the tenhan sido (eitas), principalmente pelas suas caracteristicas, tidas como de objetividade, fidedignidade e possibilidade de manipulação matemática de dados.

A Educaçăo no Brasil, em termos gerais, foi influenciada pelas 
concepcoes de medidas educacionais, sempre alinhadas em face de objetivos previamente estabelecidos e de uma determinada idéia curricular.

Nesse panorama geral, vejamos entäo como se desdobram algumas questóes específicas da avaliação educacional.

\subsection{O binômio quantidade/qualidade no processo de avaliação}

Foi a partir da década de setenta, com a Escola Nova, que a pesquisa educacional qualitativa tornou-se relevante.

Examinemos, então, os principais traços de uma e de outra, conforme diferentes autores

\section{Ouçamos SAUL ${ }^{18}$, sobre avaliação quantitativa:}

Arrola-se alguns pressupostos éticos, epistemológicos e metodologicos que expressam forte influchata do rigor positivista. Suas caracteristicas básicas definidoras âessa abordagem, podem ser assim identificadas, a partir do Sumário das proposiçoes de Gontez (1983):

- Defesa do principio de objetividade na avaliaça. A objetividade da avaliacáo, decorrenté da crenca na objetividade da ciencia, esta associada a fidedignidade e validade dos instrumontos de coleta $e$ análise de dados. O método privilegiado é o hipotético-dedutivo, proprio das ciências naturais e tradicionalmente utilizado pela psicologia experimental. 0 tratanento estatistico dos dados e a quantificaçăo das observaçoes são comumente utilizados como apoio empirico para formulaçós teóricas. As normas da metodologia. estatística exigem; operacionalizaça de variáveis, estratificação e aleatorizaça de amostras. construçăo de instrumentos de observaçấo objetiva corri suficiente grau de validade e fidedignidade, oplicaçăo de delineamentos estruturados, correlação de conjuntos de dimchsoes e trabalho com grandes populacoes (grandes numeros). A enfase maior da avaliação está quase totalmente nos produtos ou resultados. O avaliador mede o exxito docente on de um programa de ensino de modo semelhante a como o agricultor comprova a efictencia de um fertizante (mensura a situaçăo inicial, recorrendo a pré-testes; aplica um programa e, posteriomente, utiliza um pós-teste para verificar os resultados). A mensuraçäo nesse tipo de avaliaçäo, requer a operacionalizaça exaustiva das variaveis $e$ a consideraça única dos aspectos observavets do comportamento. Em consequência, deixase de Lido aspectos nem sempre previstos e frequentemente imprevisiveis. O delineamento expermental requer un controle rigoroso das variaveis intervenientes, neutralizando

19 sul, Ana Marm, of 6 , p. 42 e segs. 
algumas e manipulando e observando o efeito de outras. Busca-se simular na escola as condiçôs the laboratorio, artificializando-se, dessa forma, o ambiente escolar, A possibilidade técnica e as questões éticas implicadas nesse delineamento são alguns dos pontos criticos do modelo experimental. Este delineamento é caracterizado como o desenho mais ortodoxo dentro da abordagem quantitativa. $-O$ delineamento estruiurado do tipo pré-teste, pós-teste, de um projeto de avaliaģäo requer a permanência e estabilidade do cumculo durante um periodo prolongado de tempo, independentemente das alteraçós circunstancials que possam ocorrer durante a investigação e avaliação. - O modelo experimental busca a informaçäo quantitativa mediante meios e instrumentos objetivos. 0 problema de relevância $e$ significado dos dados näo é o centro das preocupaçóes avaliativas. Mutos aspectos, talvez de importancia critica para a análise de um programa educacional, são descartados por serem considerados anedóticos, subjetivos e impressionistas. - Há uma tendencia ao emprego de grandes amostras de casos que permitam generalizaçōes estatísticas. Os efeilos poucos usuais e interferências locais não são contemplados.

O modelo de avaliação quantitativa considera a educação como um processo tecnicista. Assume a nitida diferença entre fatos e valores, a determinação de fins e oljetivos da cducação e a neutralidade ética da intervenção tecnologica. A avaliaçäo quantitativa tem, como preocupaça única, a comprovaçăo do grau em que os objetivos previamente estabelceidos foran alcançados.

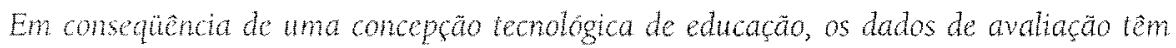
uma utilidade cspecfica para un destinatáno determinado. A autoridade responsável pelas decisöcs de planejamento dos programas educacionais é a audiència para a qual o avaliador prepara e endereça os seus relatórios. A avaliação cumpre, assim, uma funcão de apoio ao planejamento, que é externo ao processo de ensino. Este tipo de avaliaça frequentemente desconsidera os interesses e as vezes os irreconciliaveis interesses e necessidades informativas dos participantes de um programa educacional. O modelo tecnológico conduz facilmente a uma atividade avaliativa de caráter burocrätico. Na abordagcm quantitativa situam-se, pois, os modelos de avaliaçăo centrados em objetivos comportamentais, análise de sistemas e aqueles cujo enfoque está na "tomada de decisöes". (Negritos nossos).

A pesquisa em avaliação qualitativa, por seu turno, apresenta, já no inicio, o problema da pluralidade conceptual: se, para ARISTÓTELES19, a

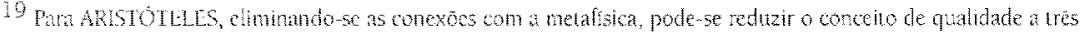

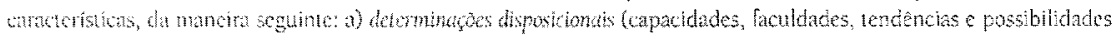

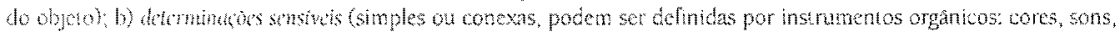

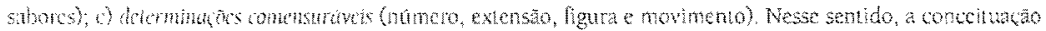

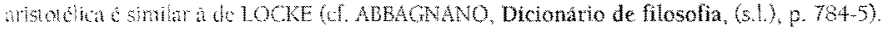


qualidade é a descrição do ser conforme é em si, para KANT20 o esquema da categoria qualidade contém e representa "a sintese da sensaça (da percepcão com a representação do tempo) ou ocupação do tempo"; enquanto que a quantidade "enche o espaço" 21.

Independentemente de diversidade do conceito, compartilha-se do ponto de vista de que a pesquisa qualitativa desenvolveu-se primeiramente na Antropologia, depois na Sociologia e, por último, na Educaçâo (onde é tambem reconhecida na espécie investigação etnográfica). Nesse sentido, TRIVIÑOS22

O aparecimento dat pesquisa qualitativa na Antropologia surgiu de maneira mais ou menos nalural. Os pesquisadores perceberam rapidamente que muitas informaçóes sobre a vida dos povos não podem ser quantificadas $e$ precisam ser interpretadas de forma muito mais ampla do que circunscrita ao simples dado objetivo. (Negrito nosso).

A investigacão qualitativa, entretanto, não significou o abandono dos posicionamentos teóricos funcionalistas e positivistas (portanto, quantitativos). Sua ação é disciplinada e orienta-se pela distinção dos elementos de avaliação em essenciais e acidentais e tambem por princípios e estratégias gerais ${ }^{23}$.

... Nenhuma concepção de avaliação, todavia, escapa da visão de homem, mundo e valores.

A dimensão metodológica primordial da pesquisa qualitativa em educaçó é partir de dados dedutivos, já que não formula objetivos a serem atingiclos; mas taça perfis e qualidades próprias do objeto que avalia. $O$ oposto ocorre com a avaliação quantitativa, na qual prevalece o método indutivo,

A pesquisa qualitativa é descritiva e preocupa-se com o processo; a quantitativa mensura e preocupa-se com o resultado ou produto.

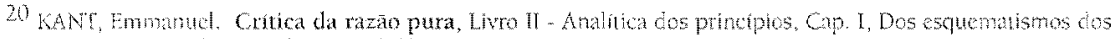

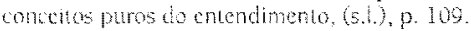

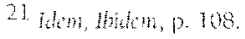

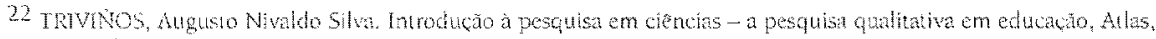
stio Thulo, 1987,120

23 dem, hadm, $\mathrm{p}+21$. 
A pesquisa qualitativa, em seus fundamentos fenomenológicos, coleta os dados e permite que se construa o perfil, característica ou qualidade, em relação ao que o próprio objeto é ou possui como valor, e não em face de padröes previamente postos.

Para tanto, há várias etapas e alternativas metodológicas, sucessivas no tempo, de modo a tornar claro que a avaliação qualitativa não se faz de uma só vez; mas paulatina e gradativamente, com a justaposição de uns dados sobre outros, sucessivamente, em distintos momentos.

\subsection{0 dificil (mas possivel) diálogo micro-macro}

A avaliação, que se faz quase sempre em relação a objetivos, planejamento, curriculos e com vistas a tomada de decisóes, é, além do diagnóstico de uma realidade, um diálogo entre o micro-sistema social (escola, curso, instituiça ou programa) com o macro-sistema social24 (contextos institucionais, burocráticos, legais, politicos, sociais, económicos, culturais, etc.).

Nessa trama de relaçoes, surgem inúmeras questóes para a atividade de avaliaça, como por exemplo, dificuldade na seleção dos aspectos a serem avaliados (especialmente nas consideraçóes qualitativas, onde existe um número infinito de descriçoes possiveis).

Incorre-se facilmente, nessas circunstâncias, no cipoal da superinformação, subinformação e pseudo-informação, sendo que escassez e excesso podem ocorrer simultaneamente ${ }^{25}$, em um mesmo instrumento.

Uma das sugestões para a administração das variáveis na integração entre o micro e o macro sistemas pode ser, para COULON26, a adoça de paradigmas, como o normativo e o sociológico.

\subsection{Taxonomias, objetivos e hierarquização}

Taxonomias, objetivos e hierarquização têm configurado uma trilogia constante e indissociavel no processo de avaliação educacional.

24 COUlon, Alain. Etnometodologia e educaça (trad. Guilherme de Freitas Teixeira), Vozes, Fetropolis, 1995.

25 ALLAN, Henri Tout, nen, peutêtue " Gưcation et vérité (Tudo, não, talvez - Educação e verdade, uad. Fâtna Casme Cortos Gaspan, Instituo Pinget, lisbon, 1993, p. 31 e também MORIN, Edgar. Para sair do sceulo XX (nat, Vera Amambuln Havey), Nova Fronteria, Rio de Janeiro, 1986.

26 Couron, Alan, an at. 
As taxonomias "dispóem de critérios precisos e objetivos de classificação, de modo que uma forma pertence a uma e a uma só categoria"2?. Para STRAUVEN28, a elaboração das taxonomias reflete a hierarquização dos objetivos.

Na opinião de LIBANEO29, a avaliação, elaborada sob diversos prismas, pode exercer, ao mesmo tempo, funçoes de diagnóstico e controle, em lace de objetivos.

Os complexos instrumentos de avaliação, especialmente na Europa ${ }^{30}$ e nos Estados Unidosi contínuam a privilegiar taxonomias e objetivos, com a elaboraçăo de"constructos" ou modelos mensuráveis, caracterizados por permitirem "rotas" ou fluxos de informaçóes, quantitativas ou qualitativas, que permitam conjugaçóes, disjunçóes e injunçóes entre si, de modo a revelar o que chamam "performances", dos projetos, das organizaçöes e dos processos, em sua dependência dos objetivos e da missão institucional ${ }^{32}$. Muitos aspectos desse modelo podem ser identificados no instrumento de avaliação DATACAPES.

Essa tendência fortaleceu-se momente após a expansão dos conceitos de "qualidade" e "qualidade total", propalados com a promulgaça dos certificados ISO. A busca desses padrões ocasionou a inserção, na Educação, de variaveis estruturais e processuais das organizações ${ }^{33}$. Desse modo, falase em eficiência e eficacia educacional; diferenciações horizontais e verticais nas avaliações, outputs e inputs, metas e participação, etc.

A seguir, vejamos o quadro sinóptico elaborado por $5 \mathrm{AUL}^{34}$, a respeito das principais vertentes genéricas da avaliaçäo educacionalcurricular:

27 STRAUVEN, Chrisiane. Construir uma formaçao-definicha de objectivos e exercicios de aplicaçăo, Asa, Lisbon, 1994, p. 103.

28 thm, ibiden.

29 LIRANEO, jose Contos Didatica. Contez, Säo Paulo, 1992.

30 GREEN, Dinat. What is quality in higher edtcation? SREE and Open Uniwersity Press, Buckingham, 1994 EILIS, Roger. Quality assurance for university teaching. Open Universily Press, Buckingham, 1994.

3I BARNES, Melwin W The practical problems of participating in experimenal projects - experimentation and evaluation (in Modern viewponts in the carriculum experimentation), McGaw Hill Conpany. New York - San. Francisco - Tomno - London, 1964

32 ELUS, Roger, op ch, p. 78 .

37 HAL, Richard H. Organizaçoes: estrutura e processos (trad. Wilma Ribeiro, 3a ed, Fd. Premice-Hall do Brasil Lida, Rio de Juneio, 1984.

34 SAUL, Ana Maria, op til, p. 36-9 
MODELOS CONTEMPORÃNEOS DE AVALIAÇĀO DE CURRICULO

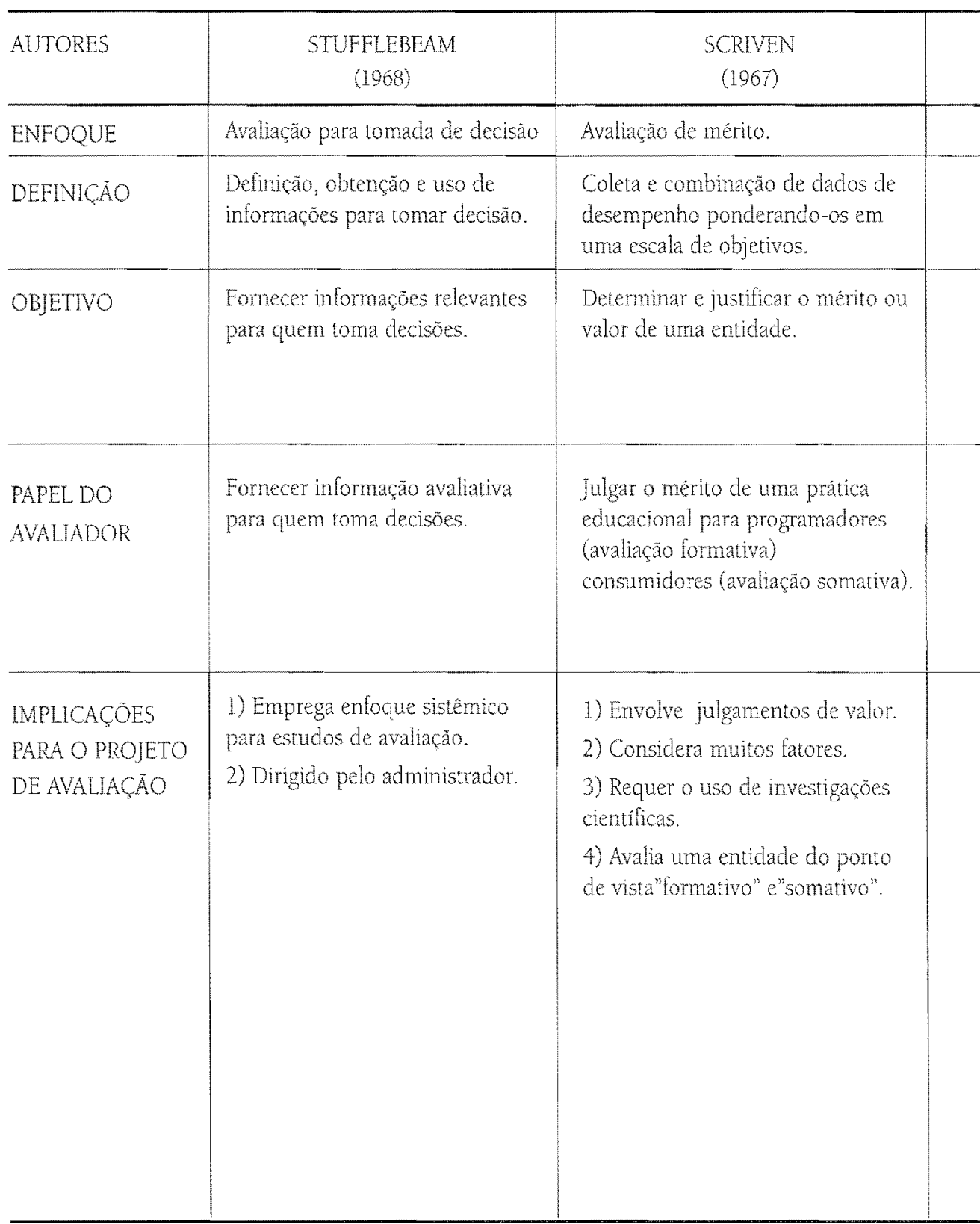


PARLETT G HAMLTON (1972)

\section{STAKE}

(1967 e 1984)
Avaliação lluminativa

Descricão interpretaço da situaça complexa de un programa de inovação.

"iluminar", lornecer compreensăo sobre a realidade estudada em sua totalidade. Verificar o impacto, a validade, a eficácia de um prograna dia inovacäo.

Observar, descrever e interpretar a situacão buscando, a) isolar suas caracteristicas significativa; b) delimitar os elos de causa e cleto; c) compreender relacoes entre as crencas e as práticas e cntre os padroes orgmizacionais e respostas dos individuos.

1) Recuer a definição de uma sistemática de observacano e registro conlínuo de eventos, interacos e de comentários inlomais.

2) Necesita de una sistematica para organizar e codificar os dados de observação.

3) Envolve coleta de informaçoes arraves de entrevistas, questionários, análise de documentos.

4) Requer a procura de principios subjacentes à organização do programa a fin de explicar as reacoes causa-efeito e situar as descobertas num contexto de pesquisa amplo.
Avaliaça responsiva.

Descricão e julgamento de um programa educacional, identifcando os seus pontos fortes racos.

Responder aos questionamentos básicos de um programa, aqueles oriundos das pessoas diretamente ligadas a ela. Considerar as reaçoes avaliativas de diferentes grupos em relação ao programa.

a) Estruturar o estudo a partir de perguntas, negociaça e selecão de questionamentos sobre o programa.

b) Coletar, processar e interpretar dados descritivos e de julgamento, fornecidos por vários grupos de pessoas.

1) Inclui matrizes para roleta e intempretaça dos dados. As matrizes preveem três compos de dados: a) antecedentes (condiçoes prévias à situaçäo ensinoaprendizagem); b) transacōes: sucessão de relaçöes que se estabelecem entre as pessoas nas diferentes situaçoes de ensino-aprendizagem; c) resuitados: consequencias do processo ensino-aprendizagem. Esse coniunto de dados permela e se cruza com quatro categorias de informação: intençes, observaçoes, padrues, julgamentos, definindo parcelas pana registro de observaçes.

2) Requer adaptação contimua dos objetivos da avaliaça dos métodos de coleta de dados, enquanto os avaliadores familarizam-se com o programae com o contexto de avaliação.

3) Permite a mclusăo de mécodos altemativos de natureza qualitativa e quantitativa. 
MODELOS CONTEMPORANEOS DE AVALIACYAO DE CURRICULO

\begin{tabular}{|c|c|c|}
\hline AUTORES & $\begin{array}{c}\text { STUFFLEBEAM } \\
(1968)\end{array}$ & $\begin{array}{c}\text { SCRIVEN } \\
(1967)\end{array}$ \\
\hline $\begin{array}{l}\text { LIMITACÖES } \\
\text { REGISTRADAS } \\
\text { NA LITERATURA }\end{array}$ & $\begin{array}{l}\text { 1) Pouca ênfase em preocupação } \\
\text { com valores. } \\
\text { 2) Processo de Tomada de } \\
\text { decisoes não é claro, metodologia } \\
\text { indefinda. } \\
\text { 3) Complexidade na utilizaçăo. } \\
\text { 4) Custo alto. } \\
\text { 5) Nem todas as atividades são } \\
\text { claramente avaliativas. } \\
\text { 6) Cisão entre avaliaça e } \\
\text { planejamento. }\end{array}$ & $\begin{array}{l}\text { 1) Comparação do desempenho em } \\
\text { relaço a diferentes critérios e } \\
\text { atribuiçäo de pesos relativos aos } \\
\text { critérios criados, ocasionando } \\
\text { problemas metodológicos. } \\
\text { 2) Ausência de previsão de } \\
\text { metodologia para calcular a } \\
\text { validade do julgamento. } \\
\text { 3) Muitos conceitos superpostos. } \\
\text { ti. }\end{array}$ \\
\hline CONTRIBUICOEES & $\begin{array}{l}\text { 1) Fonnece dacos para } \\
\text { administradores e responsáveis } \\
\text { pela tomada de decisoes, na } \\
\text { conducão de um programa. } \\
\text { 2) E sensivel ao feed-back (retro- } \\
\text { informacăo). } \\
\text { 3) Permite que a avaliacăo incida } \\
\text { em qualquer estagio do } \\
\text { programa. }\end{array}$ & $\begin{array}{l}\text { 1) Discrimina entre avaliação } \\
\text { formativa e somativa. } \\
\text { 2) Focaliza mensuraça direta do } \\
\text { valo: da entidade. } \\
\text { 3) Aplicável a varios contextos. } \\
\text { 4) Analisa meios e fins. } \\
\text { 5) Delneia tipos de avaliaça. } \\
\text { 6) Avalia objetivos. }\end{array}$ \\
\hline
\end{tabular}

(cont. do quadro da pogina anterior) 
PARLETT \& HAMILTON

(1972)
STAKE

(1967 e 1984)
1) Natureza subjetiva do método.

2) Necessidade de habilicades especiais para o avaliador. técnicas intelectuaise de relacionamento interpessoal.

3) Caracteristica de estudo de casos particulares, de inovaçoes.
D) Metodologia inadequada para obter informações a respeito de "constructos-chave".

2) Algumas celas da matriz de delineamento superpoem-se: algumas distinçoes näo estão claras.

3) Possibilidade de discussão dentro do programa ocasionando confitos de valores.

4) Natureza intuitiva e subjetiva dos dados.

5) as questoes funda mentais de avaliação Surgem näo exclusivamente dos coordenadores do programa, das agencias financiadoras ou da comunidade cientifica.

1) Fornece um méto- do sistemático para organizar e descrever dados de julgamento, assim como enfatiza inter e intra-relaça entre cles.

2) Considera padróes absolutos e relativos de julgamento.

3) Requer padrão explícito.

4) Permite generalização do modelo.

5) Comunica os resultados sob diferentes lormas. Favorecendo diferentes audiencias.

6) Enfatiza os questionamemtos, a inguagem, contexto e os padröes de julgamento das pessoas-chave do programa. 


\section{BREVE NOTA À GUISA DE CONCLUSĂO}

\section{Pudemos despreender do estudo entabulado que as diferentes} concepçóes em avaliação institucional, ao mesmo tempo em que se traduzem em instrumentos plurais e multifacetados, podem significar, igualmente, a diversidade de interpretaçăo da realidade à qual se referem.

Assim sendo, nenhuma concepção de avaliação escapa da visão de homem, mundo e valores 35 .

As diferenças entre o pensar metodológico em qualquer área do saber, inclusive em se tratando de avaliação institucional, acontecem conforme as concepçoes teórica, como exemplifica BADIOU36: "A questão dos direitos humanos estäo hoje na ordem do dia. Ora, o tema dos direitos do homem supöe a existência do homem; supóe uma idéia do homem. Finalmente, a teoria dos direitos do homem é uma certa filosofia do sujeito."

Pontanto, se a sociedade se transforma e, em consequència ou causa, transformam-se os homens que mudaram a sociedade, temos que se altera o conceito de sujeito e os discursos dele e sobre ele.

Nesse sentido, pode-se afirmar que o prosseguimento, em ampliaçăo, profundidade e perspectivas da pesquisa em avaliação institucional, é consentânea com correspondentes alteraçöes sobre o conceito de homem, enquanto sujeito de seus direitos e autor de sua própria história e cultura

\section{REFERÊNCIAS BIBLIOGRÁFICAS}

ABBAGNANO, Dicionario de filosofia, (s.1), p. 784-5).

AMORIN, Antôrio. Ayaliaçào institucional da universidade, Cortez, Săo Paulo, 1992.

ARANII, Maria lacia de Amuda. Fistóría da educaço, Modema, Sảo Paulo, 1989

ATLAN, Honti Tout, non, peutêtre - Education et vérité (trad. Fâtima Gaspar e Carlos Gaspar), Institio lagget, Lishon, 1903.

BADYOU, Ahin Para uma nova teora do sujeito, (Tad de Emerson Xaver da Glwa e Gida Sodre), in Conferenciss Brasilcins, Relume Dumara, Rio de Jnetro, 1994.

BARNES, Mewin Whe practical problems of participating in expetimental projects - experimentation and cvaluation (in Modem vewpoms in the curiculum experimentaion), McGraw-Hill Company, New York - Sam Franciso - Toronto-London, 1964.

35 Supu, item 3.1. O binônio quantidade/qualidade no processo de avaliaģăo, p. 15. 
COULON, Aan. Etnometodologia e educaça (tad. Guilherme de Freitas Teixeira), Vozes, Petropolis, 1995.

COVELLO, Sergio Carlos. Comenius - A construção da pedagogia, Sociedade Educacional Joăo Amós Comenius, Sto Fado, 1991.

DAVES, wor Kevin, O planejamento de curriculo e seus objetivos (trad. Marilia lins e Nélio Parra), Sarava, São Patulo, 1979

DURHAM, Wunce R, E SCHWARTMAN, Simon, (orgs.), Avaliação do ensino superior, Ed. USP, São Paub, 1992 HLLS, Roger. Quality assurance for uniwersity teaching, Open Univesity Press, Buckingham, 1993.

ESCOTE, Migu Angel. Universidad y devenir - entre la certeza y la incertidumbre, Lugar Editorial, Btenos Aires, 1906.

GNot7, Moncir, Historia das idéias pedagógicas, Atica, São Paulo, 1993.

GASPRIN, Joro Luiz. Comenio ou a arte de ensinar tudo a todos, Papins, Säo Paulo, 1994

GREEN, Diana $M$. What is quality in higher education? SRHE and Open University Press, Buckingham, 1994.

HALL, Rchard H. Organizaçoes: estratura e processos (trad. Wima Ribeiro), $3^{a}$ ed, Ed. Prentice-Hall do Brasil Itch?, Rio de Juncio, 1984 .

KANT, Emmanuel. Critica da razäo pura, Livo II - Analtica dos princpios, Cap. I. Dos esquematismos dos conceitos pures do cucndimento, (s).

KilLX, Abent Voco O curriculo - teoria e prática, Harper Row do brasil, Sa Pano, 1981.

KERR, Clarck Os usos da universidade (trad. Débora Cândida Dias Soares), Edições UFCE, Fortaleza, 1982.

IBAAEO, Jose Carlos. Didatica Cortez, Säo Paulo, 1992

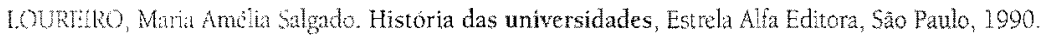

MANA, Joạmim Parron. Novos paradigmas pedagogicos - para uma filosofia da educaçăo, Paulus, Săo Paulo, 1996.

MARTNS, rum Júch Oliver. Didádita teórica, didática prática - para além do confronto, Ediçoes Loyola, São Mons, 1903

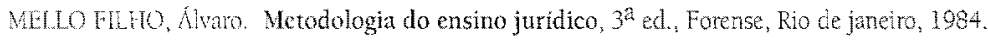

MONIN, Eggar. Para sair do sćculo XX (trad. Vera Azambuja Harvey), Nova Fronteira, Fio de Janeiro, 1986.

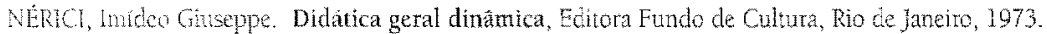

Funcoes do ensino superior (in Metodologia do ensino superior), $2^{a}$ ed. Fundo de Cultura, Rio de Janeiro, 1973

PEREZ, Jesus Murtin. O que não se fala sobre avaliacăo, (in Metodologia do ensino superior), 2a ed, Fundo de Culmat Rio de Janciro, 1973

PIUKERT, IChnu Las ciencias de la educación de la modernidad y los desafíos del presente (in Educacion, vol, 49-50), Intituto de Colaboración Ciendfica, Tubinger, 1994.

RIBEIRO, Dary. A universidade necessária, Paz e Tera, Rio de Janein, 1969

SALOMON, Ducto Veim. Tabela de avaliaça metodologica do trabaho monográfico (in Como fazer uma

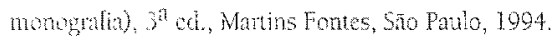

SAUl, Ana Maria. Avaliaça emancipatória - desafio à teoria e a prática de avaliação e reformulação de curriculo, $2^{i} \mathrm{ed}$. Cortez, sio Paulo, 2991.

STlGER, Kanns-Abert. As universidades no desenvolvimento social da America Latina, Editora Tempo Brasilcio, 3iv de Janeiro, 1970 .

STRAUVEN, Christiane. Construir uma formaçäo-definição de objectivos e exercicios de aplicaçă, Asa, Lisboa, 1094

ThXERA, Aniso. Ensino superior no Brasil - análise e interpretação de sua evoluçäo até 1969. Fundaça Getulo Virgis, Rio de Joneiro, 1989.

TRIVINoS, Augusto Nibaldo Silvà. Introdução à pesquisa em ciências sociais - a pesquisa qualitativa em educacăo, Arlas, sio Paulo, 1987. 